\title{
329 High Speed Machining of Bio-Titanium Alloy with a Binderless cBN Tool
}

\author{
K.HIROSAKI ${ }^{1}$, K.SHINTANI ${ }^{2}$, H.KATO ${ }^{3}$, F.ASAKURA ${ }^{3}$, and K.MATSUO ${ }^{3}$ \\ ${ }^{1}$ Industrial Research Institute of Ishikawa, 2-1Kuratsuki,Kanazawa,Ishikawa,920-8203,Japan, \\ E-mail:hiro@irii.go.jp \\ ${ }^{2}$ Kanazawa Institute of Technology,7-1 Ohgigaoka,Nonoichi,Ishikawa,921-8501,Japan, \\ E-mail:shintani@neptune.kanazawa-it.ac.jp \\ ${ }^{3}$ Kanazawa Institute of Technology,7-1 Ohgigaoka,Nonoichi,Ishikawa,921-8501,Japan
}

Summary

Using a binderless cBN tool, improvement of processing efficiency was tried in machining of a vanadium-free titanium alloy, Ti-6Al-2Nb-1Ta which was recently applied for a surgical implant material. The tool which is prepared through the direct conversion sintering of h-BN under both high pressure and temperature, exhibits an improved high temperature durability. It was confirmed that a binderless $\mathrm{cBN}$ tool exhibited lower flank wear and kept sharper cutting edge compared to the tools made of sintered carbide, conventional $\mathrm{cBN}$ with binder and polycrystalline diamond with Co-based binder, after turning in cutting speed of $4.2 \mathrm{~m} / \mathrm{s}$, feed rate of $0.15 \mathrm{~mm} / \mathrm{rev}$,depth of cut of $0.5 \mathrm{~mm}$ under an application of a high pressure coolant. Also, milling tests were conducted with a radius end mill tool which was made of the binderless $\mathrm{cBN}$ material. The possibility of high speed cutting in milling process was found.

Keywords: bio-titanium alloy, binderless $\mathrm{cBN}$ tool, tool wear, high speed machining

\section{Introduction}

Although surgical implants as a stem of an artificial hip joint are standardized in several specifications, their variations in size and form are not enough to fit every patient. To make them fit to any patients, it is required that these implants can be manufactured rapidly by machining with application of the patient's medical image data obtained by MRI or X-ray CT. And recently titanium alloys without containing vanadium are going to applied for material of surgical implant in place of conventional type of titanium alloy such as Ti-6Al-4V system, in order to eliminate a toxicological effect of vanadium for human body ${ }^{(1)(2)}$. In 2002 year, these materials were standardized as titanium alloys for surgical implant in the Japanese Industrial Standard.

By the way, the temperature rise in the cutting edge is significant in cutting process of titanium alloys including above mentioned vanadium-free alloys, promoted strongly the adhesion between tool and work materials in general, resulting in tool failure within relatively short duration ${ }^{(3)(4)(5)}$. So, in order to improve processing efficiency of cutting of titanium alloys, a binderless cBN tool was suggested to apply in cutting of the conventional Ti-6Al-4V alloy in the previous report ${ }^{(6)}$. It was confirmed that a binderless cBN tool exhibited lower flank wear and kept sharp cutting edge.

In this report, improvement of processing efficiency by using a binderless $\mathrm{cBN}$ tool was investigated in machining of Ti-6Al-2Nb-1Ta, which was one of above described vanadium-free titanium alloys. A binderless $\mathrm{cBN}$ tool which was prepared through the direct conversion sintering of $\mathrm{h}$-BN under both high pressure and temperature, exhibited an improved high temperature durability ${ }^{(7)}$. In this work, turning tests and milling tests were conducted, then cutting performance were evaluated.

\section{Experimental procedure}

The used workpiece was Ti-6Al-2Nb-1Ta, which was one of vanadium-free titanium alloys were applied for bio-medical implant materials without containing vanadium. Table 1 shows the chemical compositions and mechanical properties of the workpiece material. The alloy is the same $\alpha+\beta$ type as Ti-6Al-4V which is popular in industry because vanadium contained in Ti-6Al-4V is replaced with niobium and tantalum which make $\beta$ phase in $\alpha+\beta$ type alloy be stable in Ti-6Al-2Nb-1Ta alloy. Therefore the mechanical properties of the alloy are similar to that of Ti-6Al-4V alloy.

Table1 Chemical compositions and mechanical properties of the workpiece material

\begin{tabular}{c|c|c|c|c|c|c|c|c|c|c}
\hline \multirow{2}{*}{$\begin{array}{c}\text { Workpiece } \\
\text { material }\end{array}$} & \multicolumn{4}{|c|}{ Chemical composition (mass\%) } & \multicolumn{2}{c|}{$\begin{array}{c}\text { Brinell } \\
\text { Hardness } \\
\mathrm{HB}\end{array}$} & $\begin{array}{c}\text { Tensile } \\
\text { Strength } \\
\mathrm{MPa}\end{array}$ & $\begin{array}{c}\text { Elonga- } \\
\text { tion } \\
\%\end{array}$ & $\begin{array}{c}\text { Heat } \\
\text { treatment }\end{array}$ \\
\cline { 2 - 10 } Ti-6Al-2Nb-1Ta & 5.96 & --- & 2.00 & 1.06 & 0.78 & $\mathrm{Nal}$ & 280 & 912 & 16 & Annealed \\
\hline
\end{tabular}


Table2 Materials and characteristic of the used tools

\begin{tabular}{|c|c|c|c|c|c|c|}
\hline \multicolumn{2}{|l|}{ Tool type } & $\begin{array}{c}\text { Main } \\
\text { component }\end{array}$ & $\begin{array}{l}\text { Content ratio of } \\
\text { main component } \\
\text { (vol\%) }\end{array}$ & $\begin{array}{l}\text { Grain } \\
\text { size } \\
(\mu \mathrm{m})\end{array}$ & $\begin{array}{l}\text { Material of } \\
\text { binding phase }\end{array}$ & $\begin{array}{l}\text { Vickers } \\
\text { Hardness } \\
\text { HV(R.T.) }\end{array}$ \\
\hline Cemented carbide(K10) & [WC] & $\mathrm{WC}$ & 92 & $<1$ & Co & 1750 \\
\hline Sintered cubic boron nitride & [PcBN] & $\mathrm{cBN}$ & 80 & 5 & Co & 4000 \\
\hline Polycrystalline diamond & [PCD] & Diamond & 85 & 5 & Co & 7000 \\
\hline $\begin{array}{c}\text { Binder-less sintered } \\
\text { cubic boron nitride }\end{array}$ & ess-cBN] & $\mathrm{cBN}$ & $>99.9$ & $<1$ & None & 5000 \\
\hline
\end{tabular}

In this experiment, in order to investigate the cutting performance of a binderless $\mathrm{cBN}$ tool and several conventional tools, turning tests of cutting of Ti-6Al-2Nb-1Ta alloy were conducted. The material and characteristic of the tools tested are shown in Table 2. A cemented carbide tool (WC), a sintered cubic boron nitride tool $(\mathrm{PcBN})$, a polycrystalline diamond tool (PCD) with Co-based binder and a binderless sintered cubic boron nitride tool (Binderless-cBN) were tested. The tools were throw-away type of square inserts and the tool geometries were $(-5,-5,5,5,15,15,0.8)$ with the width of the edge chamfer to $0.02 \mathrm{~mm}$. A binderless $\mathrm{cBN}$ tool is synthesized by direct conversion sintering of h-BN under both high pressure and temperature, and consists of c-BN crystalline phase of over $99.9 \%$. The tool made of binderless $\mathrm{cBN}$ has high durability up to $1350{ }^{\circ} \mathrm{C}$ because of non-binder ${ }^{(7)}$

Turning tests were conducted under the conditions shown in Table 3. The cutting speed adapted was $4.2 \mathrm{~m} / \mathrm{s}$ with the constant feed rate of $0.15 \mathrm{~mm} / \mathrm{rev}$ and $0.5 \mathrm{~mm}$ depth of cut. In the case of using the binderless $\mathrm{cBN}$ tool, the cutting tests were carried out in various cutting speeds of $1.7-6.0 \mathrm{~m} / \mathrm{s}$. Emulsion type coolant was used as the cutting fluid at a diluting rate of 1:30. The cutting fluid was poured from the rake face side of the tool with pressure of $30 \mathrm{MPa}$. The coolant nozzle was fixed at $30 \mathrm{~mm}$ apart from the nose of tip and declined with 25 degrees against the rake face. The tool life was determined by measuring the width of flank wear (VB) or failing. The VB was defined as the mean distance between the initial cutting edge and front of a worn portion. Measurements were performed on the used tools after etching in hydrofluoric acid to remove any unbounded titanium on the tool face.

Milling tests were also conducted under the conditions shown in Table 4. A radius end mill tool was used in milling tests. The schematic overview of the holder and the insert is shown in Fig.1. The tested tips were round inserts which were made of binderless $\mathrm{cBN}$ material. They are the diameter of $8 \mathrm{~mm}$ and can be fixed in their specified holder. The insert is set at 3 degrees of negative rake angle in axial direction and 0 degree of rake angle in radial direction. The cutting fluid was poured through the
Table 3 Cutting conditions in turning tests

\begin{tabular}{l|l|l}
\hline \multicolumn{1}{c||}{ Workpiece } & \multicolumn{2}{c}{ Ti-6Al-2Nb-1Ta } \\
\hline \multirow{2}{*}{ Tool material } & $\begin{array}{l}\cdot \text { WC } \\
\text {-PcBN } \\
\text {-PCD }\end{array}$ & $\begin{array}{c}\text { Binderless- } \\
\text { cBN }\end{array}$ \\
\hline Tool geometry & $(-5,-5,5,5,15,15,0.8)$ \\
\hline Cutting speed $(\mathrm{m} / \mathrm{s})$ & 4.2 & $\begin{array}{l}1.7,3.0,4.2, \\
5.0,6.0\end{array}$ \\
\hline Feed rate $(\mathrm{mm} / \mathrm{rev})$ & \multicolumn{2}{|c}{0.15} \\
\hline Depth of cut $(\mathrm{mm})$ & \multicolumn{2}{|c}{0.5} \\
\hline \multirow{2}{*}{ Coolant } & \multicolumn{2}{|l}{$\begin{array}{l}\text { Fluid:Emulsion type } \\
\text { Diluting rate:1:30 } \\
\text { Feeding pressure:30MPa }\end{array}$} \\
\hline
\end{tabular}

Table4 Cutting conditions in milling tests

\begin{tabular}{c||c}
\hline Workpiece & Ti-6AI-2Nb-1Ta \\
\hline Tool material & Binderless- cBN \\
\hline Tool geometry & $\begin{array}{c}\text { Radius end mill, Diameter: } \phi 20 \\
\text { Diameter of Around insert: } \phi 8 \\
\text { Axial rake:-3 } 3^{\circ}, \text { Radial rake: } 0^{\circ}\end{array}$ \\
\hline Cutting speed $(\mathrm{m} / \mathrm{s})$ & $3.0,5.0,8.3$ \\
\hline Depth of cut $(\mathrm{mm})$ & 0.2 \\
\hline Pick feed $(\mathrm{mm})$ & 0.5 \\
\hline Feed rate $(\mathrm{mm} /$ tooth) & 0.05 \\
\hline Cutting direction & Down cut \\
\hline Coolant & $\begin{array}{l}\text { Fluid:Emulsion type } \\
\text { Diluting rate: } 1: 30 \\
\text { Feeding pressure:5MPa } \\
\text { *Feed through inside hole } \\
\text { Diameter of Hole }: 1 \mathrm{~mm}\end{array}$ \\
\hline
\end{tabular}
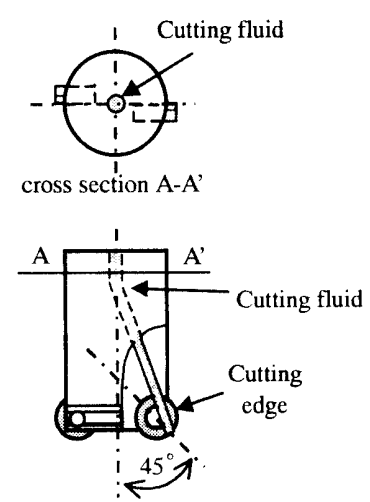

Fig.1 Schematic overview of the used tool 
spindle and holder onto the rake side of the cutting edge. The feeding pressure was $5 \mathrm{MPa}$. Workpiece is leaned 45 degrees to the horizontal plane for the purpose that the actual cutting edge is the vicinity area of 45 degrees in the around insert tip.

\section{Experimental results and discussion}

3.1 Comparison of tool life

The performance of tools was evaluated in cutting of the Ti-6Al-2Nb-1Ta alloy. Fig. 2 shows the comparison of tool lives for the tools at cutting speed of $4.2 \mathrm{~m} / \mathrm{s}$. The limited value of VB to terminate the life was set as $0.1 \mathrm{~mm}$. Fig. 3 shows the SEM images of the tool cutting edge reached tool life, and the forms of the rake face of tools obtained by measuring with a surface roughness tester are shown in Fig.4.

As shown in Fig.2, the life of WC tool was the shortest, resulting in reaching the tool life at the cutting length of only $70 \mathrm{~m}$. On the rake face of this tool, the severe crater wear are observed in addition to the progressive wear on the flank face, and its edge is even deformed practically as seen in Fig.3(a) and Fig.4(a). The lives of PcBN tool and PCD tool were longer than that of WC tool, corresponded to the cutting length of $250 \mathrm{~m}$ and $600 \mathrm{~m}$ respectively, but they will not be practically used in the industry. And in both tools, the wear of the cutting edge were not reduced so much but the crater wear were so progressive at reaching tool life as shown in Fig.3(b),(c) and Fig.4(b),(c). The progress of this wear pattern fears to occur a breakage of the cutting edge. It is considered that the wear of three tools mentioned above proceeded severely because the temperature at the cutting edge would be raised and exceeded the limits of temperature durability of these tools at the cutting speed of $4.2 \mathrm{~m} / \mathrm{s}$. Although both WC and PCD tools are usually known as suitable for machining of the titanium alloys, their performance was not necessarily high.

On the other hand, the Binderless-cBN tool was so superior in wear resistance to other tools. The cutting length of $3300 \mathrm{~m}$ is over five times as long as that of PCD tool. As shown in Fig.3(d), the tool edge was kept sharp even after $3300 \mathrm{~m}$ at the cutting length, and the crater wear of the rake face did not progress so much as seen in Fig.4(d). It argues that the binderless $\mathrm{CBN}$ tool has a high durability.

3.2 Influence of cutting speed on tool life

Using the binderless $\mathrm{cBN}$ tool the cutting test was carried at a variety of cutting speed in order to investigate the influence of cutting speed on tool life. In this test, the VB value to determine the tool life was set as $0.1 \mathrm{~mm}$. Fig.5 shows the relations between the cutting speed and the tool life. And the photomicrographs of the rake face of tool at reaching tool life are shown in Fig.6. As shown in Fig.5, the tool life at cutting speed of $4.2 \mathrm{~m} / \mathrm{s}$ was the longest in the various cutting speeds, and it means that a suitable region of cutting speed exists under a certain condition. The tool life of the cutting speed of $1.7 \mathrm{~m} / \mathrm{s}$ was about $600 \mathrm{~m}$ cutting length. This is attributed to the aggressive adhesion between the tool material and the

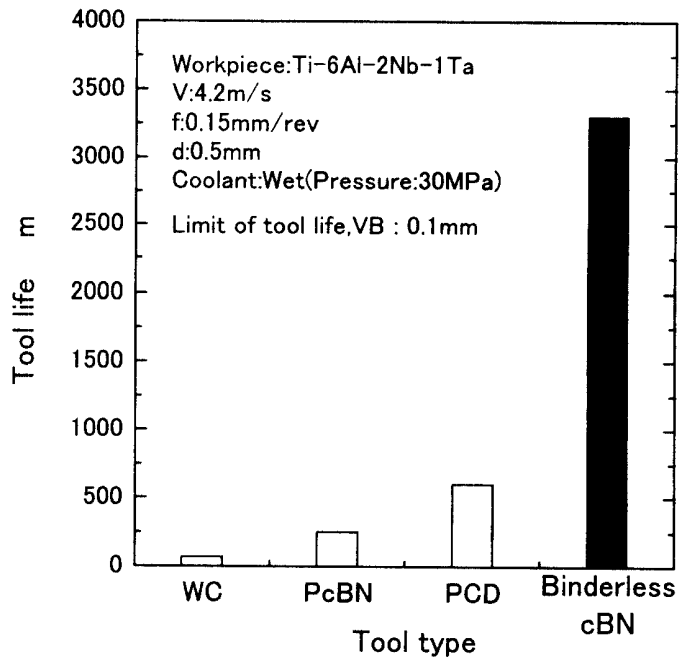

Fig.2 Comparison of tool wear of various tools

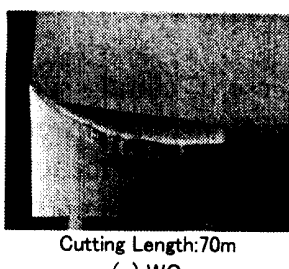

(a) WC

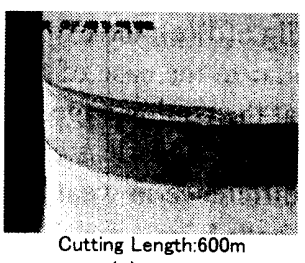

(c) PCD

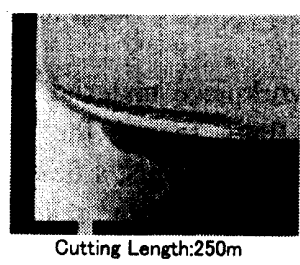

(b) PcBN

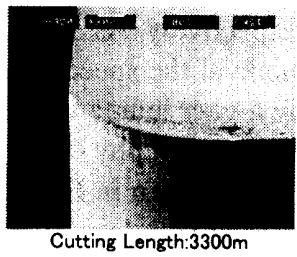

(d) Binderless-cBN
Fig.3 SEM images of cutting edges of various tools at reaching tool life

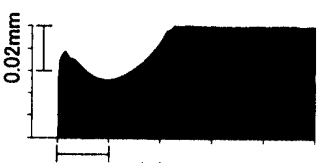

(a) WC

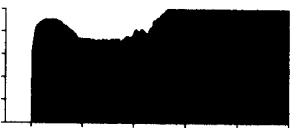

(c) PCD

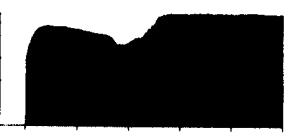

(b) PcBN

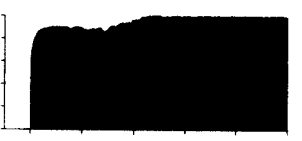

(d) Binderless-cBN
Fig.4 Forms of the rake face of various tools 


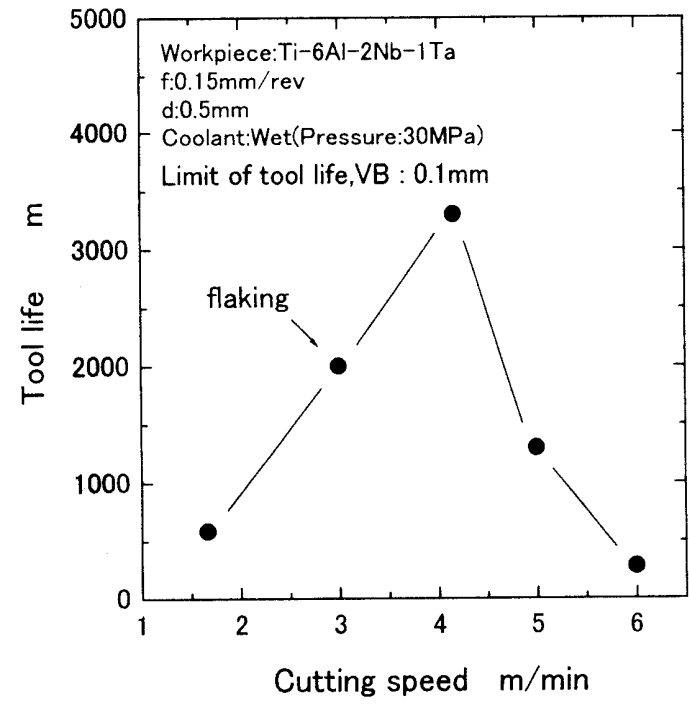

Fig.5 Relation between cutting speed and tool life using binderless cBN tools

workpiece material. In the case of cutting speed of $3.0 \mathrm{~m} / \mathrm{s}$, though the flank wear rate was lower than that of $4.2 \mathrm{~m} / \mathrm{s}$, a flake which determined the tool life occurred on the rake face as shown in Fig.6(b), resulting in reaching tool life at cutting length of $2000 \mathrm{~m}$ in spite of the VB value of approximately $0.04 \mathrm{~mm}$. On the other hand, at cutting speed of $5.0 \mathrm{~m} / \mathrm{s}$ and $6.0 \mathrm{~m} / \mathrm{s}$, the flank wear progressed was so rapidly, resulting in the tool lives of $1300 \mathrm{~m}$ and $300 \mathrm{~m}$ cutting length respectively. As shown in Fig.6(d)(e), the extended crater wear was observed on the rake face. Since the wear mode at the speed was similar to the case of the WC tool at the speed of $4.2 \mathrm{~m} / \mathrm{s}$, the shortest life was caused by higher temperature rise at the cutting edge.

3.3 Topography on tool face of a binderless $\mathrm{cBN}$ tool

As seen in Fig.6, the difference in wear mode was observed according to the cutting speeds. In the case of relatively low speeds of both $1.7 \mathrm{~m} / \mathrm{s}$ and $3.0 \mathrm{~m} / \mathrm{s}$, the roughness of the rake faces in the cutting edge region were coarse, and a few flakes on the cutting edges were found. On the other hand, in relatively high cutting (a) $V: 1.7 \mathrm{~m} / \mathrm{s}$
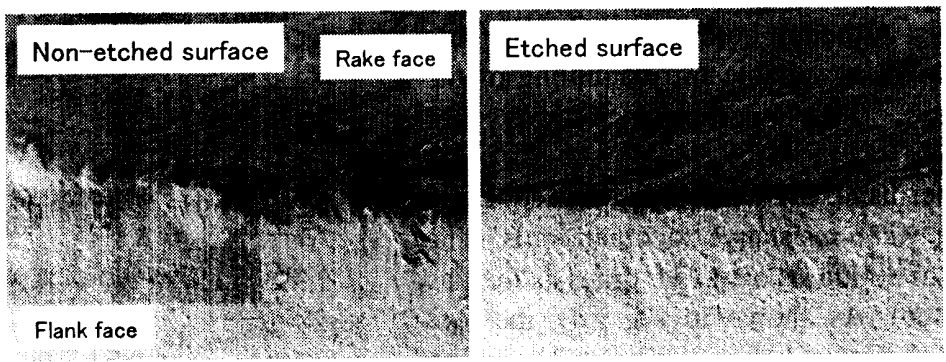

(b) $V: 6.0 \mathrm{~m} / \mathrm{s}$

$50 \mu \mathrm{m}$
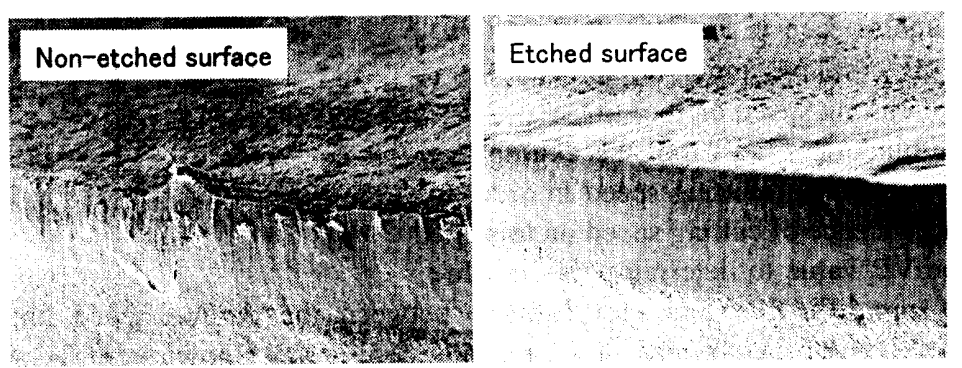

Fig.7 Comparison of wear mode of the cutting edge for the cutting speeds of $1.7 \mathrm{~m} / \mathrm{s}$ and $6.0 \mathrm{~m} / \mathrm{s}$ at a cutting length of $50 \mathrm{~m}$ 
speeds such as $4.2 \mathrm{~m} / \mathrm{s}, 5.0 \mathrm{~m} / \mathrm{s}$ and $6.0 \mathrm{~m} / \mathrm{s}$, the roughness were fine, and the rake faces of the cutting edges looked smooth though some scratches were observed on the rake face backward the cutting edge for the case of $4.2 \mathrm{~m} / \mathrm{s}$ cutting speed.

Fig. 7 shows the SEM images of the cutting edges at the cutting length of $50 \mathrm{~m}$ in earlier stage of the cutting process. The SEM images of the tools used under the cutting speed of $1.7 \mathrm{~m} / \mathrm{s}$ and $6.0 \mathrm{~m} / \mathrm{s}$ were shown as typical conditions. It is observed that both of the tools are covered with much of adhesive after cutting. And as seen in SEM images of the tools after etching in hydrofluoric acid to remove any adhesive on the tool face, in the cutting edge of the speed of $1.7 \mathrm{~m} / \mathrm{s}$, many small flakes occurred on both the rake and flank face. On the other hand, in the case of $6.0 \mathrm{~m} / \mathrm{s}$ the smooth surface was observed not only on the rake face but also on the flank face in the earlier stage of cutting process, in spite of occurring a few flakes. Here, in order to clarify the relation between the cutting speed and the topography of the cutting edge, the surface roughness of the tool rake face at reaching tool life was evaluated. The surface roughness was measured by using a 3-D surface structure analyzer shown in Fig.8. The evaluated area size of the tool rake face was $0.07 \mathrm{~mm} \times 0.05 \mathrm{~mm}$ with a high pass filter (cut-off value:0.025mm). Fig. 9 shows the relation between the cutting speed and the surface roughness of the tool rake face. In the case of relatively low cutting speeds of $1.7 \mathrm{~m} / \mathrm{s}$ and $3.0 \mathrm{~m} / \mathrm{s}$ the roughness was higher than an initial roughness on a virgin surface, and in relatively high cutting speed of more than $4.2 \mathrm{~m} / \mathrm{s}$ the roughness was so much lower. It is considered this mechanism was caused by a thermal and chemical reaction in an interface between the tool face and the workpiece with generated cutting temperature in the tool edge, and the reaction controlled flaking or promoting a tool wear in a cutting edge.

3.4 Cutting performance of a binderless $\mathrm{cBN}$ tool in milling process

The cutting performance of a binderless $\mathrm{cBN}$ tool was evaluated in milling of the Ti-6Al-2Nb-1Ta alloy. Fig.10 shows the variation of the width of the flank wear land with an increase in cutting length at various cutting speeds. In this figure, the cutting length means the integrated length in which a cutting edge actually

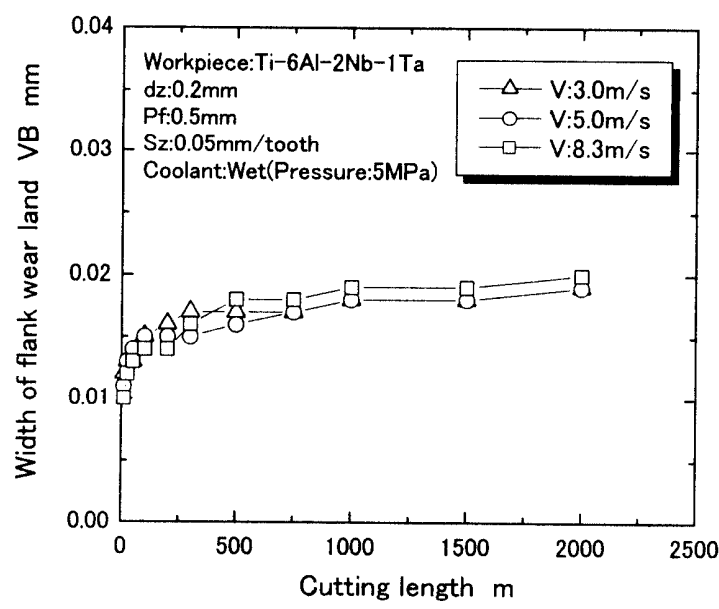

Fig.10 Variation of the VB value with an increase

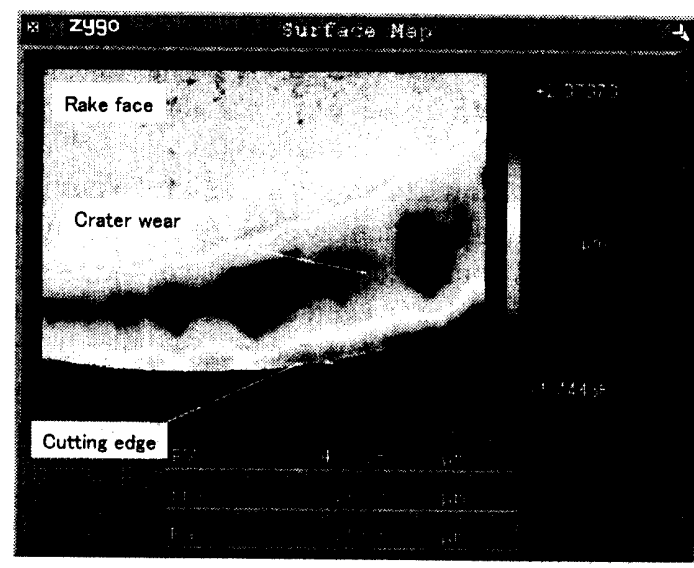

Fig.8 Measurement of 3-D surface roughness using a 3-D surface structure analyzer

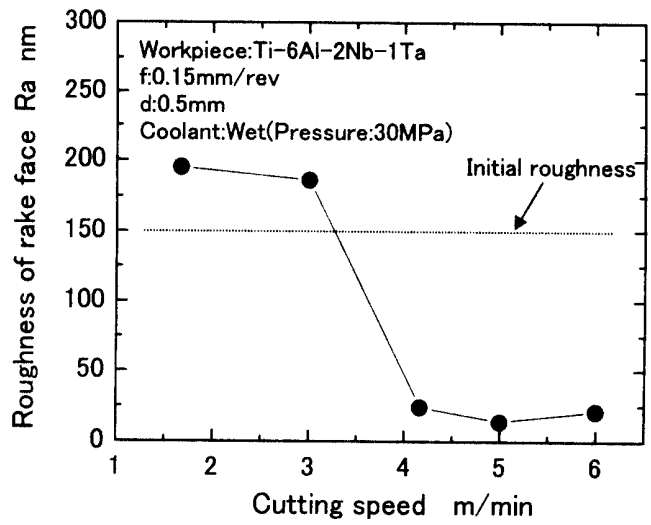

Fig.9 Relation between cutting speed and surface roughness of tool rake face

\section{in cutting length at various cutting speeds}

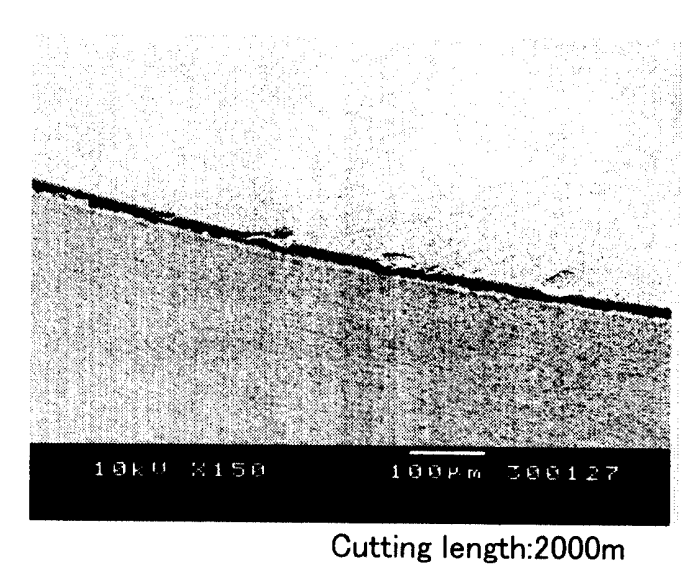

Fig.11 SEM image of the cutting edge with a Round insert in milling test at the cutting speed of $8.3 \mathrm{~m} / \mathrm{s}$ 
cuts the workpiece. The milling tests were stopped at reaching the cutting length of $2000 \mathrm{~m}$ in all of the cutting speeds. As shown in Fig.10, no remarkable difference in tool wear was found in each of the cutting speeds. The VB value was only about $0.02 \mathrm{~mm}$ at the cutting length of $2000 \mathrm{~m}$ even in cutting speed of $8.3 \mathrm{~m} / \mathrm{s}$.

Fig.11 shows the SEM image of the cutting edge at the cutting length of $2000 \mathrm{~m}$ in the cutting speed of $8.3 \mathrm{~m} / \mathrm{s}$. Though the tool was not etched in hydrofluoric acid, almost no adhesive on the cutting edge were observed as compared with the case of the turning tests. As shown in Fig.11, some small flakes in the cutting edge were found, however, both of the flank wear and the crater wear were not so much progressed. Also, the smooth layer on the cutting edge was not observed. It is thought the smooth layer was not reacted even the cutting speed of $8.3 \mathrm{~m} / \mathrm{s}$ because the temperature rise in the cutting edge was not significant under the fine condition such as this milling test. Therefore, the possibility of higher speed milling than $8.3 \mathrm{~m} / \mathrm{s}$ cutting speed was found under this condition.

\section{Conclusions}

Cutting performance was evaluated in machining of Ti-6Al-2Nb-1Ta, which was a vanadium free titanium alloy for surgical implant material, using a binderless cBN tool. The results obtained are summarized as follows:

(1) The wear resistance of a binderless $\mathrm{cBN}$ tool was so superior to those of the tools made of cemented carbide, PcBN and polycrystalline diamond with Co-based binder.

(2) The tool life at cutting speed of $4.2 \mathrm{~m} / \mathrm{s}$ was the longest in several cutting speeds using a binderless $\mathrm{cBN}$ tool in this experiment condition.

(3) The roughness of the tool edge was higher than an initial one on a virgin tool surface in the case of relatively low cutting speed, on the other hand, in high cutting speed of more than $4.2 \mathrm{~m} / \mathrm{s}$ the roughness of the reacted tool face was so much lower.

(4) Milling tests were conducted with a radius end mill tool which was made of binderless cBN material. The possibility of high speed milling at cutting speed of over $8.3 \mathrm{~m} / \mathrm{s}$ was found under this condition.

\section{References}

(1)SASAKI Y., DOI K. and MATSUSHITA T., Titanium Alloys for Artificial Hip Joint, Metal\&Technology, 1996, 66(9), pp.812-817.(in Japanese)

(2)OKAZAKI Y., ITO Y., ITO A. and TATEISHI T., Effect of Alloying Elements on Mechanical Properties of Titanium Alloys for Medical Implants, J.Japan Inst.Metals, 1993, 57(3), pp.332-337.(in Japanese)

(3)P.D.Hartung and B.M.Kramer, Tool Wear in Titanium Machining, Annals of the CIRP, 1982, 31(1), pp.75-80.

(4)NARUTAKI N., MURAKOSHI A. and MOTONISHI S., Study on Machining of Titanium Alloys, Annals of the CIRP, 1983, 32(1), pp.65 69 .

(5)USUKI H., NARUTAKI N. and YAMANE S., Study on Turning of Ti-3Al-8V-6Cr-4Mo-4Zr, J. of JSPE, 1995, 61(7), pp.1001-1005.(in Japanese)

(6)HIROSAKI K., SHINMURA S., SHINTANI K., KATO H. and NISHIMURA S., Fundametal Machining Characteristics of Bio-Titanium Alloys, Progress of Machining Technology, 2002, pp.64-69.

(7)H.Kato, K.Shintani and H.Sumiya, Cutting performance of a binder-less sintered cubic boron nitride tool in the high-speed milling of gray cast iron, Journal of Materials Processing Technology, 127(2002), pp.217-221. 